\title{
PRML 方式に対する消失誤り訂正方式の一検討 \\ A Study of Erasure Error Correction for a PRML System
}

\author{
岡本好弘 - 大坪 純 - 大沢 寿 - 仲村泰明 - 村岡裕明 ${ }^{*}$. 中村慶久 ${ }^{*}$ \\ 愛媛大学工学部，愛媛県松山市文京町 3( ₹ 790-8577) \\ "東北大学電気通信研究所，仙台市青葉区片平 2-1-1 (广980-8577)
}

\author{
Y. Okamoto, J . Ohtsubo, H. Osawa, Y. Nakamura, H. Muraoka*, and Y. Nakamura* \\ Faculty of Engineering, Ehime University, 3 Bunkyo-cho, Matsuyama-shi, Ehime 790-8577, J apan \\ *Research Institute of Electrical Communication, Tohoku University, 2-1-1 Katahira, Aoba-ku, Sendai 980-8577, J apan
}

In a hard disk drive (HDD), a postprocessor is used for correcting the random error in a PRML (Partial Response Maximum Likelihood) channel. However, the postprocessor needs an error-detecting code, such as a single parity check code, and the code rate decreases. This paper proposes an erasure correction by Reed-Solomon (RS) code using Squared-DistanceIncrease (SDI) instead of a postprocessor. This system does not need any error detecting code. The performance is obtained by computer simulation and is compared with that of the error correction system using a postprocessor. The results show that the proposed system provides an SNR improvement of about $2.6 \mathrm{~dB}$ compared with the system using a postprocessor in a perpendicular magnetic recording channel with random and burst errors.

Key words: perpendicular magnetic recording, PRML, RS code, SDI, postprocessor

\section{1. まえがき}

近年 ,ハードディスク装置 (HDD : Hard Disk Drive) の高密 度化力圂躍的に進み，更なる高密度記録を達成するために誤り訂 正方式，記録符号，PRML (Partial Response Maximum Likelihood)方式などの信号処理方式力必須の技術となっている. 現行の HDD ては，誤り訂正符号としてバースト誤りを効率良く 訂正することかできるReed-Solomon (RS) 符号が使われている . 但し，RS符号による訂正を行う前に，ランダム誤りを減らすため

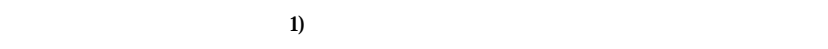
単一パリティ符号等による誤り検出力必要であるために, システ 么全体の符号化率力低下するという問題がある . 本論文では, ポ ストプロセッサの代わりに RS 符号に対する消失誤り訂正の適用 につて検討を行う。

\section{2. 記録再生系}

Fig.1に,RLL (Run Length Limited) 符号化をRS 符号化 に対して前置した RLL-RS 符号化 PRML 方式に, 誤り位置情報 として SDI (Squared-Distancelncrease) 》を用いる誤り訂正を 適用した記録再生系ブロック图を示す.現行のHDD てはRLL 符 号化PRML 方式ての復号誤りを訂正するために , 光の外側にRS 符号化・復号化を設けている.これに対して本方式ては，ビタビ 復号器出力と等化器出力より求めた SDI を誤り位置情報としで消 失誤り訂正を行うために，RLL 符号化・復号化を RS 符号化・復
号化の外側に置いている. また, 誤り訂正前にRLL 符号の復号化 を行うと,PRML 方式における誤りが, RLL 符号の復号化て複数 符号ビットに拡大されて RS 符号を用いた誤り訂正の負担か大と なる ${ }^{2}$.これは, 高符号化率RLL 符号を構成するために符号長が 長くなり RLL符号の復号化て誤り拡大力顕著になる ${ }^{3}$.しかし， 本方式のようにRLL 符号の復号を行う前にRS 符号を用いて誤り 訂正を行うことで，PRML 方式において生じた誤りか䇊大される 前に誤り訂正を行える。

Fig.1における2值入力データ系列 $\left\{a_{k^{n}}\right\}$ は,RLL 符号化器を通 ることにより符号系列 $\left\{b_{k^{\prime}}\right\}$ に変換される。但し，RLL 符号とし て 128/130(0,16/8)符号 3)を用いる.更に，次式て表されるプリコ

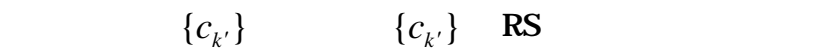
録デー久系列 $\left\{e_{k}\right\}$ 力得られる.RS 符号化器出力系列 $\left\{e_{k}\right\}$ を記 録電流波形として, 記録ヘッドから記録媒体にNRZ記録を行う.

$$
c_{k^{\prime}}=b_{k^{\prime}}+c_{k^{\prime}-2}
$$

ここては，ステップ状の記録波形に対する孤立再生波形を，

$$
h(t)=A \tanh \left(\frac{\ln 3}{T_{50}} t\right)
$$

と仮定する.但し, $A=\lim _{t \rightarrow \infty} h(t)$ は $h(t)$ の飽和レベル,$T_{50}$ は $h(t)$ が- $A / 2$ から $A / 2$ まて変化するのに要する時間であり， 規格化線密度 $K_{\mathrm{p}}$ は $T_{50} / T_{\mathrm{b}}$ て定義する.但し， $T_{\mathrm{b}}$ はビット間融で ある.また, 杂隹音として磁化遷移点力白色ガウス性に変動するジ ッ多性媒体杂隹音, 及ひ平均值が 0 の白色ガウス杂倠音を仮定し, 読 み出し点における SN 比を，

$$
\mathrm{SNR}=20 \log _{10} \frac{A}{\sqrt{\sigma_{\mathrm{J}}^{2}+\sigma_{\mathrm{W}}^{2}}}
$$

て定義する.但し， $\sigma_{\mathrm{J}}^{2}$ 及び $\sigma_{\mathrm{W}}^{2}$ は，乥れ光れ $0.6 f_{\mathrm{b}}$ の帯域にお けるジッ性媒体雑音, 白色ガウス雑音の電力であり， $f_{\mathrm{b}}=1 / T_{\mathrm{b}}$ はビットレートである . また, 読み出し点における全雑音電力に

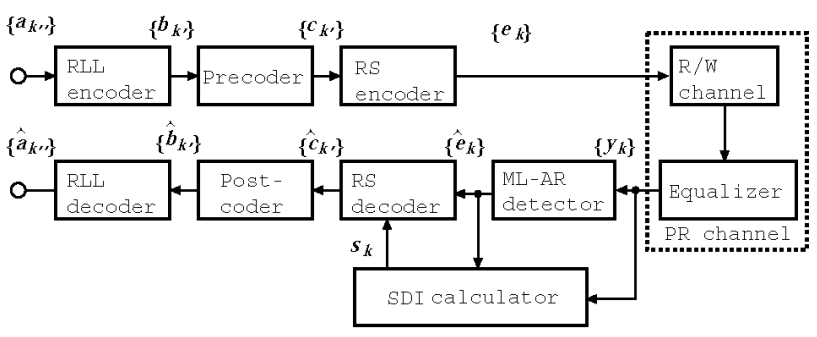

Fig. 1 Block diagram of PRML system with RS encoder and decoder. 
対するジッタ性媒体杂倠音の割哈を次式て定義する．

$$
R_{\mathrm{J}}=\frac{\sigma_{\mathrm{J}}^{2}}{\sigma_{\mathrm{J}}^{2}+\sigma_{\mathrm{W}}^{2}} \times 100
$$

再生波形は，ビットレート $f_{\mathrm{b}}$ て規格化した遮断周波数 $x_{\mathrm{h}}$ を持 つ6次バタワース・ローパスフィルタとタッフ数が $N_{\mathrm{t}}$ のトランス バーサルフィルタからなる等化器でPR1特性となるように波形等 化される.次いで, AR (Autoregressive) チャネルモデルを適用 したビタビ復号器4により復号か行われる.ビタビ復号器出力に対 してRS 符号による誤り訂正を行うが, このとき,等化器出力とビ タビ復号器出力より求めたSDI を用いて誤り位置を決定し, 消失 誤り訂正を行う . また, RS 復号器出力からプリコーダの逆特性を 持つポストコーダにより $\left\{\hat{b}_{k^{\prime}}\right\}$ が得られる.更に 128/130(0,16/8) 復号化器により出力データ系列 $\left\{\hat{a}_{k^{\prime}}\right\}$ に復号される.乥して,入力 データ系列と出力データ系列を比較することにより，ビット誤り 率 (BER) 力求められる.

\section{3. 符号化方式}

Fig.2 に符号化の手順を示す.まず， 1 セクタに相当す る入力データ系列 4096 ビットを 128/130(0,16/8)符号化し， 4160 符号ビットの RLL 符号系列を得る . 128/130(0,16/8) 符号は“ 0” の連続長を 0 16 符号ビットに制限し, 更に 偶数および奇数に分割した各部分系列における゙ 0” の最大 連続長を 8 符号ビット以下に制限する RLL 符号である。 128/130(0,16/8)符号化された系列を，10符号ビットをガロ ア体 GF $\left(2^{10}\right)$ 上の 1 シンボルとして $(464,416,49) R S$ 符号化 する .ここで, $(464,416,49) R S$ 符号は 416 シンボルのデー タ語を 464 シンボルの符号語に符号化し, 最小ハミング距 離は 49 となる.光のため, この RS 符号は 1 符号語内に発 生する 24 シンボル以内の誤りを訂正することができる.但 し，RS 符号化して得られた符号語の冗長部分は RLL の制 約を満たしていない可能性があるので, 16 符号ビットごと にガードビットを挿入し，RLL の制約を確保する.ここで， 全体の符号化率は 0.877 である.

4096 bits

4160 code bits $\downarrow \quad 128 / 130(0,16 / 8)$ RLL encoding

$128 / 130=0.9846$

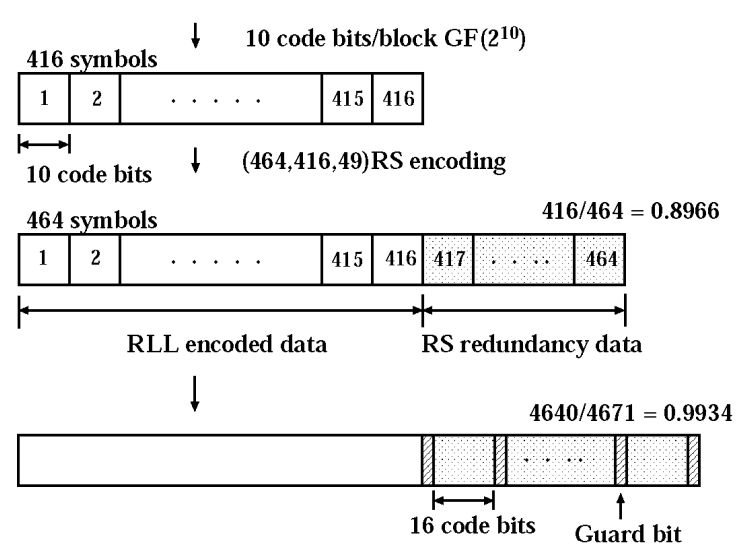

Fig. 2 Encoding for RLL - RS system.

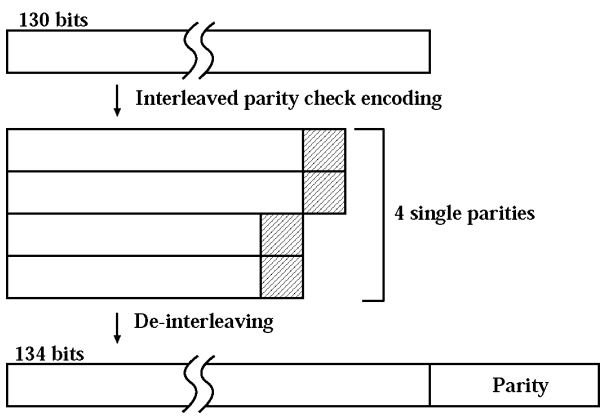

Fig. 3 Interleaved parity coding.

一方，本論文で比較対象としたポストプロセッサによる 誤り訂正を行う方式でも先に示した 24 シンボル誤りを訂 正できる $(464,416,49) R S$ 符号を使用する.但し，RLL の制 約を満たすためにガードビットを挿入した後，ポストプロ セッサでの誤り検出のためにインタリーブドパリティ符号 化を行う．インタリーブドパリティ符号化の手順を Fig.3 に示す.インタリーブドパリティ符号化は $128 / 130(0,16 / 8)$ 符号化された 1 符号語に相当する 130 符号ビットを 1 ブロ ックとして符号化する．まず，ビット単位に4インタリー ブして各行に単一パリティを付加し，得られた 134 チャネ ルビットを再びディインタリーブして記録系列とする . 再 生時には,Fig.3の各行に対してパリティ検査を行う.1ブ ロック内に発生した誤りが 1 事象であれば，光の誤りパタ ーンと誤りが始まる行を絞り込むことができる．これら候 補の中から SDI が低い位置を誤り位置と判定して, 誤り訂 正を行う。したがって，RS 符号によるシンボル単位の誤り 訂正の負担を軽減することが期待できるものの，パリティ 符号化により全体の符号化率は 0.851 に低下してしまう. 一方，本論文て提案する方式は，ポストプロセッサによる 訂正を行う代わりに消失誤り訂正を行うため，パリティ符 号化による符号化率の低下がなく，これによる性能改善が 期待できる . また，パリティ符号化に与える冗長を RS 符 号に割り当て，RS 符号の訂正能力を 30 シンボルまで上げ た $(476,416,61) R S$ 符号を適用すればバースト誤りに対す る而性を強化することも可能である．

\section{PRML 方式}

2.で述べたように本論文ては, 微分特性を持なない垂直磁気記 録再生系の伝達特性に合せてPR1方式を適用している，また，垂 直磁気記録再生系においては, 機器杂倠音だけてなな, 磁化遷移点 変動に起因するジッタ性媒体杂倠音の影響を低減する必要がある。 そこで, 信号依存性杂倠音を予測する AR チャネルモデルを適用し たビタビ復号器のブロック图をFig.4に示す このビタビ復号器は， 図のようにメトリックの計算部，AR チャネルモデル 杂隹音メモリ， パスメモリから構成されている.ビタビ復号器入力 $y_{k}$ から信号 系列参照表出力 $x_{k}^{i j}$ を引くことより得られる $k$ 時点における雑 音の候補 $\tilde{n}_{k}^{i j}$ が $L \times 2^{L-1}$ の杂倠音メモリに入力される. 光して，メ トリックの計算結果を基に杂隹音メモリを更新することにより，各 状態に対応した杂隹音メモリ内の值 $n_{k}^{i}$ か求まる.杂隹音メモリ内の值 


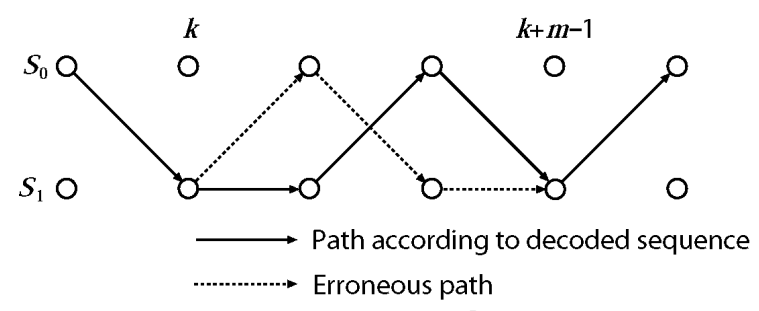

Fig. $4 \mathrm{ML}$ - AR detector.

と杂隹音予測係数 $e_{\mathrm{L}}(\beta)$ を畳み込むことで 1 L チャネルビット過 去の雑音から予測した杂倠音レベル $n_{k}^{i j}$ を求める.このように $\mathrm{AR}$ チャネルモデルを用いたビタビ復号器においては, 杂隹音も含めて 推定值を求めて最尤復号を行う.但し，AR チャネルモデルの信号 表, 杂隹音係数表を予め求めておく必要がある.

\section{SDI による消失位置の決定}

消失誤り訂正を行うためには消失シンボルを特定する必 要がある. 兴のための情報として, 復号器における復号信 頼性情報 1),5),6) ,TA(Thermal Asperity)やドロップアウトな どに対する検出フラグが考えられる．本論文では消失シン ボルを特定するために SDI を用いる．Fig.5に，PR1ML 方式におけるトレリス線図の例を示す.図中の実線は復号 結果に対応するパス，破線は誤りパスを表している．図の ように，時刻 $k$ において特定の誤りパターンが発生したと 仮定して，SDI の計算を行う.時刻 $k$ において長さ $m$ の誤 りパターンを仮定したときのSDI は次式で定義され, ビタ ビ復号器の復号信頼度を表す ${ }^{11}$. 但し "“+ + - 0” の誤りの 場合では $m=3$ となる .

$$
s_{k}^{m}=d_{k}^{2}-d_{k}^{\prime 2}
$$

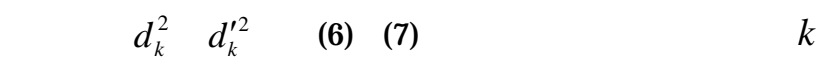
におけるビタビ復号器の復号結果に対応する等化器出力 $y_{k}$ の推定值 $x_{k}$ と $y_{k}$ との 2 乗ユークリッド距離, 長さ $m$ の 誤りパターンを仮定したときの $y_{k}$ の推定值 $x_{k}^{\prime}$ と $y_{k}$ との 2 乗ユークリッド距離を表している.

$$
\begin{aligned}
& d_{k}^{2}=\sum_{n=k}^{k+m-1}\left(x_{n}-y_{n}\right)^{2} \\
& d_{k}^{\prime 2}=\sum_{n=k}^{k+m-1}\left(x_{n}^{\prime}-y_{n}\right)^{2}
\end{aligned}
$$

本論文では,このようにして求まる SDI を消失誤り訂正に 用いる方法を提案する . まずビタビ復号器の復号結果に対 して $m=1 \sim 5$ チャネルビットに渡る復号誤りを仮定して $s_{k}^{m}$ を計算し, 弚の中で最も低いSDI を時刻 $k$ でのSDI と して採用する. RS 符号はガロア体 GF $\left(2^{10}\right)$ 上のシンボル単 位で誤り訂正を行うため,チャネルビット単位で求めた $s_{k}^{m}$ の中で最も低いSDI をガロア体 GF $\left(2^{10}\right)$ 上の SDI として採 用し，これを $s_{k_{\mathrm{RS}}}$ とする.但し， $k_{\mathrm{RS}}$ はシンボル単位の時 刻とする.この $s_{k_{\mathrm{RS}}}$ が最も低いシンボルから順番に消失位 置として選びRS 符号による消失誤り訂正を行う.Fig.6に
$\mathrm{SDI}$ と誤り位置の関係を示す . 但し $, R_{\mathrm{J}}=90 \%{ }^{7)}, K_{\mathrm{p}}=1.5$, $N_{\mathrm{t}}=0.4, \mathrm{SNR}=20.6 \mathrm{~dB}$ としている . 図において, 横軸はガ ロア体 GF $\left(2^{10}\right)$ 上のシンボル間隔 $T_{\mathrm{RS}}$ で規格化した時間 縦 軸は $s_{k_{\mathrm{RS}}}$ を表している．また，图中の×印は実際に誤りが 発生した位置でのSDI を示している 図からわかるように， SDI が低い位置は実際にも誤っている可能性が高く, SDI が低いシンボルを消失とすることで, 効果的な消失誤り訂 正が期待できる.Fig.7にバースト誤りを含むセクタのSDI と誤り位置の関係を示す . 但し , バースト長は 200 ビット とし $, R=90 \%, K_{\mathrm{p}}=1.5, N_{\mathrm{t}}=0.4, \mathrm{SNR}=23.5 \mathrm{~dB}$ としてい る.図からわかるように, バースト誤りの位置でも，SDI の值が低くなっている. 产のため, バースト誤りに対して もSDI を利用できることがわかる .

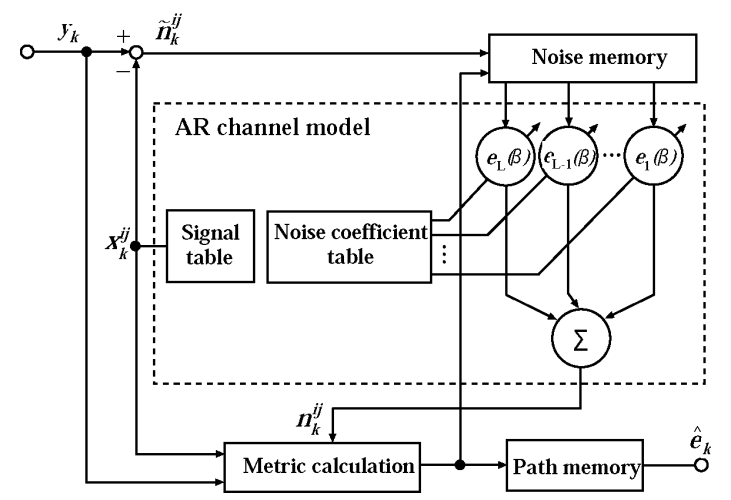

Fig. 5 Trellis diagram for PR1ML system.

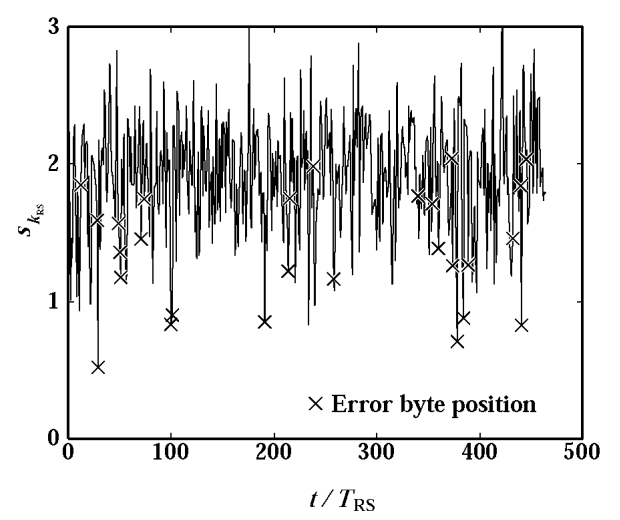

Fig. 6 Example of SDI in RS decoder. $\left(R_{\mathrm{J}}=90 \%, K_{\mathrm{p}}=1.5, \mathrm{x}_{\mathrm{h}}=0.4, \mathrm{SNR}=20.6 \mathrm{~dB}\right)$

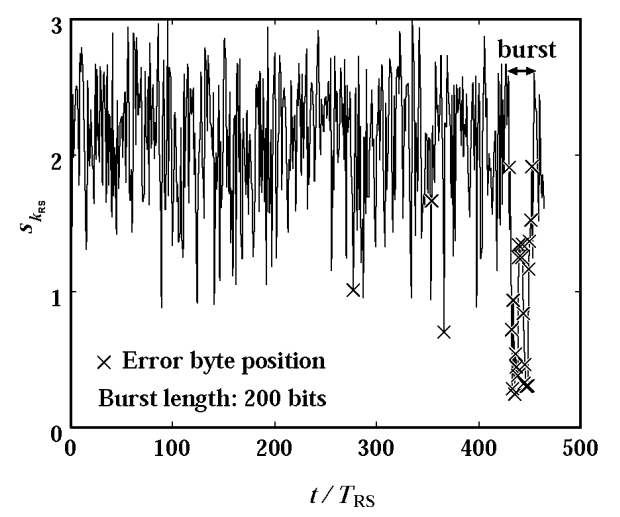

Fig. 7 Example of SDI around burst error. $\left(R_{\mathrm{J}}=90 \%, K_{\mathrm{p}}=1.5, \mathrm{x}_{\mathrm{h}}=0.4, \mathrm{SNR}=23.6 \mathrm{~dB}\right)$ 


\section{6. 性能比較}

Fig.8に,計算機シミュレーションにより求めた BER 特 性を示す . 但し , $R \mathrm{~J}=90 \%, K_{\mathrm{p}}=1.5, N_{\mathrm{t}}=0.4, L=5$ として いる．図中の印は比較対象としたポストプロセッサによ る訂正を行う方式の場合を示している .これに対しての印 はポストプロセッサによる訂正を行わない代わりに RS 符 号による消失誤り訂正を行った場合を示している．この方 式ではパリティ符号化を行う必要がないため，印の場合 に比へて符号化率が改善され，印の方式よりも良好な特 性が得られている。印は四印の方式がパリティ符号に与 える冗長を RS 符号に割り当てて訂正能力を上げた場合を 示している。印とロ印を比較すると，ランダム誤りに対 しては RS 符号の訂正能力を上げることによる改善は得ら れていないが, RS 符号の訂正能力を上げたことでバースト 誤りに対する而性が向上していると考えられる．

Fig.9に 読み出し点においてバーストをセクタあたりー 度だけ発生させた場合の BER 特性を示す．但し，バース 卜は再生信号が 0 となるように与え, RS 符号の訂正能力 の限界に近い誤りが発生した場合の性能を比較するため， バースト長は 200 ビットとした . また，RS 符号は組織符 号であるため, RS 符号のパリテイ部分にバーストを与える と，誤りを訂正することができなかった場合でも復号によ ってバースト誤りを除去してしまうため, バーストを与え る位置は RS 符号のパリティ部分以外の位置とした . とO印では, RS 符号の訂正能力は等しいが,ポストプロセ ッサによる訂正を行うよりも，符号化率改善と消失誤り訂 正を行う方が良好な特性を示すことがわかる．また，○印 は先に示したように, バースト誤りに対する耐性の向上か ら期待された性能を示し，印に対して $10^{7}$ ユーザービッ 卜中に誤り無しとなる SN 比を約 $2.6 \mathrm{~dB}$ 改善できることが わかる．これより，ランダム誤りとバースト誤りが存在す る場合はバーストの程度によって RS 符号の訂正能力を上 げることも有効であることがわかる .

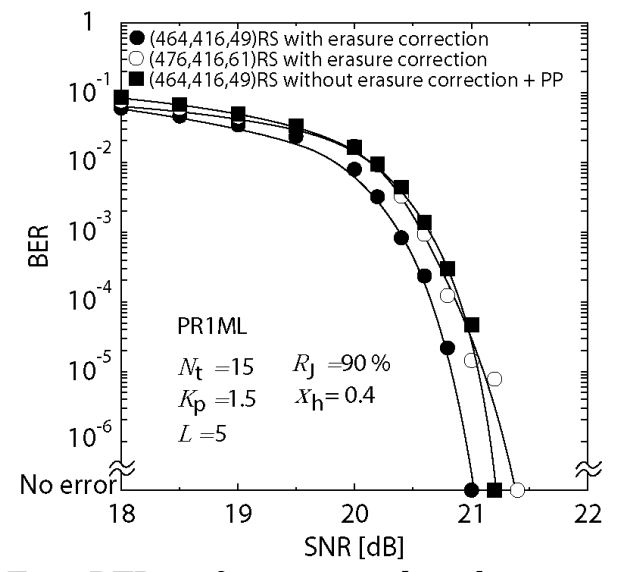

Fig.8 BER performance without burst error.

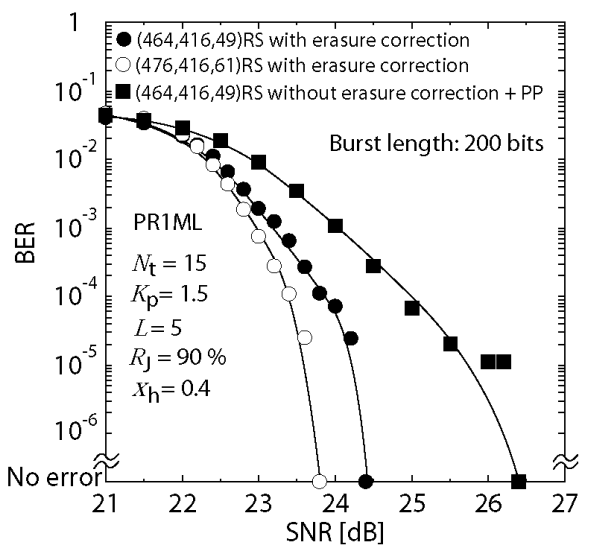

Fig. 9 BER performance with burst error.

\section{7. むすび}

本論文では,垂直磁気記録におけるPRML 方式に対して， ランダム誤りを減らすために用いられるポストプロセッサ の代わりに RS 符号による消失誤り訂正を行う方式の性能 評価を計算機シミュレーションにより行い, ポストプロセ ッサによる誤り訂正を行う方式と比較検討を行った .

兴の結果，符号化率の改善により RS 符号による消失誤 り訂正を行う方が良好な特性が得られることが明らかとな った . また，パリティ符号化のための冗長を RS 符号に割 り当てることで, バースト誤りに対する恧性が向上し , バ ースト誤りとランダム誤りの混在する場合には更に良好な 特性が得られることが明らかとなった .

謝辞 日頃，有益なご助言を賜わる尾道大学田崎三郎教授 に深謝いたします．また，本研究の一部は情報ストレージ 研究推進機構 (SRC) の助成のもとに行ったものであるこ とを付記し，謝意を表します．

\section{References}

1)Zining Wu: Coding and Iterative Detection for Magnetic Recording Channels, p. 103(Kluwer Academic Publishers, Massachusetts, 2000).

2)H. Kamabe: Proc. The 2001 IEICE Society Conference, Tokyo, 2001, SC-4-4(The Institute of Electronics, Information and Communication Engineers, Tokyo, 2001).

3)H. Saito, T. Iga, M. Sirakawa, Y. Okamoto, and H. Osawa: IEICE Trans. Electron., J 86-C, 952(2003).

4)Y. Okamoto, N. Masunari, H. Yamamoto, H. Osawa, H. Saito, H. Muraoka, and Y. Nakamura: IEICE Technical Report, MR2001-92(2002).

5)H. Yamamoto, K. Itoh: Viterbi Decoding Algorithm for Convolutional Codes with Repeat Request, IEEE Trans. Inform. Theory, vol. 26, pp. 540- 547(1980).

6)J. Hagenauer and P. Hoeher: A Viterbi algorithm with softdecision outputs and its applications, Proc. IEEE GlobeCom, pp. 1680- 1686(1989).

7) H. Osawa, Y. Okamoto, and H. Saito: IEICE Trans. Electron, J 81-C- II (4), 393(1998).

2004 年 10 月 7 日受理，2004 年 12 月 14 日採録 